http://jmscr.igmpublication.org/home/

ISSN (e)-2347-176x ISSN (p) 2455-0450

crossref DOI: https://dx.doi.org/10.18535/jmscr/v7i7.11

\title{
Reliability of MR Fistulogram in the Surgical Management of Fistula-In- Ano
}

\author{
Authors \\ Dr Naresh Kumar Damerla, DNB (Gen Surg) \\ Dr Thogari Kranthi Kumar, DNB (Gen Surg)* \\ *Corresponding Author \\ Dr Thogari Kranthi Kumar, DNB (Gen Surg)
}

\begin{abstract}
Absract
A fistula is defined as an abnormal connection between two structures or organs or between an organ and the surface of the body. In case of perianal fistula, it is an abnormal connection between anal canal and perianal skin.

In the past, imaging techniques played a limited role, but now it is increasing, especially the use of MRI. In this study we tried to correlate MRI and intra-operative findings and discussed the usefulness of MRI in surgical management of perianal fistula.

MRI is able to adequately evaluate and classify perianal fistula disease with a high degree of accuracy.

Keywords: fistula-in-ano, MRI, intraoperative findings.
\end{abstract}

\section{Introduction}

A fistula is defined as an abnormal connection between two structures or organs or between an organ and the surface of the body. In case of perianal fistula, it is an abnormal connection between anal canal and perianal skin. This defect is characterized by three basic components: internal opening as primary opening in the anal canal, fistulous tract and external opening as secondary opening in the perianal skin. It is an inflammatory condition that affects perianal region causing significant morbidity and often requiring repeated surgical interventions due to its high tendency to recur.

Prevalence of perianal fistula is approximately 10 in 1,00,000, affecting males 2-4 times more frequently than females. ${ }^{1}$ Anal fistulas are diagnosed following drainage of perianal abscess in $25-37 \%$ of cases. ${ }^{2-3}$ They are usually diagnosed following recurrence of the abscess. The most common presenting symptom is discharge (65\%), but local pain is frequent due to inflammation. ${ }^{4}$ Antibiotic therapy does not have an effect on the development of fistulae following abscess drainage. ${ }^{5}$ The management priorities follow three central and sequential principles: control of sepsis, closure of the tract, and preservation of sphincter function. One of the treatment of fistula is surgical management, which is successful in most cases but it is associated with significant recurrence. ${ }^{6}$ Successful surgical management requires accurate preoperative assessment of the course of primary tract and site of any secondary extension/ abscesses. $^{7}$ 
In the past, imaging techniques played a limited role, but now it is increasing, especially the use of MRI as it provides more precise information on the anatomy of anal canal, sphincter complex, and relationship of fistula to the pelvic floor structures and to the plane of levator ani muscle. It allows identification of primary tracts and abscesses or secondary extensions, which is not possible on physical examination, thereby allowing surgeons to choose the best surgical treatment, reducing recurrence of disease or possible complications, such as feacal incontinence. ${ }^{8,9}$

In this study, we review the role of imaging techniques in evaluation of perianal fistula and characterise the findings in detail according to the type of primary tract (park's classification), location of internal opening, length of the tract, secondary tracts and abscesses. We then correlated MRI and intra-operative findings and discussed the usefulness of MRI in surgical management of perianal fistula.

\section{Materials and Methodology}

Source of Data: Patients admitted with fistula-inano at ST.ISABEL'S HOSPITAL.

Study Period: September 2015 to March 2017.

Aprospective observational study.

A total number of 30 patients were studied.

Demographic data was obtained from all patients and they were examined clinically and standard data was collected. They were subjected for 3Tesla MRI. All of the MR Images were reported by a single senior radiologist of more than 10years experience.

The following findings were compared between MRI and intra-operatively. Primary tract was considered as per park's classification. Internal opening was considered as whether it's opening anterior or posterior. Length of the primary tract was measured in MRI and intra-operatively. Then other findings like abscess/secondary tracts/horse shoe tract were observed in MRI and intraoperatively whether present or absent.

\section{Inclusion Criteria}

1. Patients with anal fistula.
2. Patients who gave consent and planned for operative management.

\section{Exclusion Criteria}

1. Patients who were in acute pain.

2. Recurrent fistula.

3. Patients who underwent anal procedure earlier.

4. Patients having associated malignant disease.

\section{Results}

\section{MRI Findings}

Table 1: Descriptive Analysis of Primary Tract Type in MRI

\begin{tabular}{|l|c|c|}
\hline PRIMARY TRACT & Frequency & Percentage \\
\hline Inter-sphincteric & 25 & $83.33 \%$ \\
\hline Trans-sphincteric & 5 & $16.66 \%$ \\
\hline
\end{tabular}

25 cases were inter-sphincteric $(83.33 \%)$ and 5 cases were trans-sphincteric $(16.66 \%)$.

Table 2: Descriptive Analysis of Internal Opening in MRI

\begin{tabular}{|l|c|c|}
\hline Internal opening (MRI) & Frequency & Percentage \\
\hline Anterior & 13 & $43.33 \%$ \\
\hline Posterior & 17 & $56.66 \%$ \\
\hline
\end{tabular}

13 cases $(43.33 \%)$ were found to have internal opening anteriorly and 17 cases posteriorly $(56.66 \%)$.

Table 3: Analysis of Secondary Tracts/ Abscess/ Horse Shoe Tract in MRI $(\mathrm{N}=30)$

\begin{tabular}{|l|c|c|}
\hline MRI findings & Frequency & Percentage \\
\hline Secondary tract & 10 & $33.33 \%$ \\
\hline Abscess & 11 & $36.11 \%$ \\
\hline Horseshoe tract & 1 & $3.33 \%$ \\
\hline
\end{tabular}

10 cases were found to have secondary tracts (33.33\%), 11 cases had abscess $(36.11 \%)$, and 1 case had horse-shoe tract (3.33\%).

\section{Per-Operative Findings}

Table 4: Descriptive Analysis of Primary Tract Per-Operatively $(\mathrm{N}=30)$

\begin{tabular}{|l|c|c|}
\hline $\begin{array}{l}\text { Primary Tract (PER- } \\
\text { OPERATIVELY) }\end{array}$ & Frequency & Percentage \\
\hline Inter-sphincteric & 26 & $86.66 \%$ \\
\hline Trans-sphincteric & 4 & $13.33 \%$ \\
\hline
\end{tabular}

26 patients were identified as inter-sphincteric $(86.66 \%)$ and 4 patients as trans-sphincteric type $(13.33 \%)$. 
Table 5: Descriptive Analysis of Internal Opening in Per-Operatively

\begin{tabular}{|l|c|c|}
\hline $\begin{array}{l}\text { Internal opening } \\
\text { (PER-OP) }\end{array}$ & Frequency & Percentage \\
\hline Anterior & 12 & $40 \%$ \\
\hline Posterior & 18 & $60 \%$ \\
\hline
\end{tabular}

12 patients were identified as internal opening at anterior $(40 \%)$ and in 18 cases internal opening at posterior $(60 \%)$.

Table 6: Descriptive Analysis of other per operative findings $(\mathrm{N}=30)$

\begin{tabular}{|l|c|c|}
\hline Parameter & Frequency & Percentage \\
\hline Secondary tract & 9 & $30.0 \%$ \\
\hline Abscess & 13 & $43.3 \%$ \\
\hline Horseshoe tract & 1 & $33.33 \%$ \\
\hline
\end{tabular}

9 cases were with secondary tracts (30\%), 13 cases were with abscess (43.03\%), and 1 patient was with horse shoe extension (33.33\%).

\section{Agreement between MRI and Per-Operative Findings}

Table 7: Association of Primary Tract in MRI vs Per-op (N=30)

\begin{tabular}{|l|c|c|c|c|}
\hline \multirow{2}{*}{$\begin{array}{l}\text { Primary } \\
\text { Tract-Mri }\end{array}$} & \multicolumn{2}{|c|}{$\begin{array}{c}\text { Primary Tract Per- } \\
\text { Operatively }\end{array}$} & \\
\cline { 2 - 5 } & $\begin{array}{c}\text { Inter- } \\
\text { Sphincteric }\end{array}$ & $\begin{array}{c}\text { Trans- } \\
\text { Sphincteric }\end{array}$ & $\begin{array}{c}\text { Chi } \\
\text { Square }\end{array}$ & $\begin{array}{c}\text { P- } \\
\text { Value }\end{array}$ \\
\hline $\begin{array}{l}\text { Inter- } \\
\text { Sphincteric } \\
\text { (N=25) }\end{array}$ & $25(100 \%)$ & $0(0 \%)$ & & \\
\hline $\begin{array}{l}\text { Trans- } \\
\text { Sphincteric } \\
\text { (N=5) }\end{array}$ & $1(20 \%)$ & $4(80 \%)$ & 23.077 & $<0.001$ \\
\hline
\end{tabular}

MRI showed inter-sphincteric type in 25 cases and the same number were identified intra-operatively (100\%). MRI showed 5 cases as trans-sphincteric typebut intra operatively 4 cases $(80 \%)$ were found as trans-sphincteric tracts and other 1 case identified as inter-sphincteric type $(20 \%)$ $(\mathrm{p}=<0.001)$.

Table 8: Predictive Validity of MRI in Identifying primary Tract

\begin{tabular}{|l|c|c|c|}
\hline \multirow{2}{*}{ Parameter } & \multirow{2}{*}{ Value } & \multicolumn{2}{|c|}{$95 \%$ CI } \\
\cline { 3 - 4 } & & Lower & Upper \\
\hline Sensitivity & $96.15 \%$ & $81.1 \%$ & $99.32 \%$ \\
\hline Specificity & $100.00 \%$ & $100 \%$ & $100 \%$ \\
\hline $\begin{array}{l}\text { False positive rate } \\
\text { (FPR) }\end{array}$ & $1 \%$ & $0 \%$ & $1 \%$ \\
\hline
\end{tabular}

\begin{tabular}{|l|c|c|c|}
\hline $\begin{array}{l}\text { False negative rate } \\
\text { (FNR) }\end{array}$ & $3.85 \%$ & $-3.54 \%$ & $11.23 \%$ \\
\hline $\begin{array}{l}\text { Positive predictive } \\
\text { value (PPV) }\end{array}$ & $100.00 \%$ & $86.68 \%$ & $100 \%$ \\
\hline $\begin{array}{l}\text { Negative predictive } \\
\text { value (NPV) }\end{array}$ & $80.00 \%$ & $37.55 \%$ & $96.38 \%$ \\
\hline $\begin{array}{l}\text { Diagnostic } \\
\text { accuracy(DA) }\end{array}$ & $97 \%$ & $83.33 \%$ & $99.41 \%$ \\
\hline
\end{tabular}

Sensitivity: $96.15 \%$ ( 95 CI 81.1 TO 99.32).

Specificity: $100 \%$ (95 CI $100 \%$ to $100 \%$ ).

FPR: $1 \%$ (95 CI 0\% to $1 \%$ ).

FNR: $3.85 \%(95$ CI -3.54to 11.23).

PPV: $100.00 \%$ (95 CI 37.55 to 96.38 ).

NPV: $80.00 \%$ (95 CI 37.55to 96.38).

DA: $97 \%(95$ CI 83.33 to 99.41 ).

Table 9: Association of Internal Opening: Per-op vs MRI $(\mathrm{N}=30)$

\begin{tabular}{|c|c|c|c|c|}
\hline \multirow{2}{*}{$\begin{array}{l}\text { Internal } \\
\text { Opeing } \\
\text { (MRI) }\end{array}$} & \multicolumn{2}{|c|}{$\begin{array}{c}\text { Internal Opening } \\
\text { (Per Op) }\end{array}$} & \multirow[b]{2}{*}{$\begin{array}{c}\text { Chi } \\
\text { Square }\end{array}$} & \multirow[b]{2}{*}{$\begin{array}{c}\text { P- } \\
\text { Value } \\
\end{array}$} \\
\hline & Anterior & Posterior & & \\
\hline $\begin{array}{l}\text { Anterior } \\
(\mathrm{N}=13)\end{array}$ & $12(92.30 \%)$ & $1(7.692 \%)$ & \multirow{2}{*}{26.154} & \multirow{2}{*}{$<0.001$} \\
\hline $\begin{array}{l}\text { Posterior } \\
(\mathrm{N}=17)\end{array}$ & $0(0 \%)$ & $17(100 \%)$ & & \\
\hline
\end{tabular}

MRI showed internal opening anteriorly in 13 cases but intra operatively 12 cases had internal opening anteriorly $(92.32 \%)$ and other one case posteriorly (7.692\%).17 cases were identified internal opening posteriorly both in MRI and intra-operatively $(100 \%)(\mathrm{p}=<0.001)$.

Table 10: Predictive Validity of MRI in Identifying Internal Opening

\begin{tabular}{|l|c|c|c|}
\hline \multirow{2}{*}{ Parameter } & \multirow{2}{*}{ Value } & \multicolumn{2}{|c|}{ 95\% CI } \\
\cline { 3 - 4 } & & Lower & Upper \\
\hline Sensitivity & $100.00 \%$ & $75.75 \%$ & $100 \%$ \\
\hline Specificity & $94.44 \%$ & $74.24 \%$ & $99.01 \%$ \\
\hline FPR & $5.56 \%$ & $-5.02 \%$ & $16.13 \%$ \\
\hline FNR & $0.00 \%$ & $0 \%$ & $24.25 \%$ \\
\hline PPV & $92.31 \%$ & $66.69 \%$ & $98.63 \%$ \\
\hline NPV & $100.00 \%$ & $81.57 \%$ & $100 \%$ \\
\hline DA & $97 \%$ & $83.33 \%$ & $99.41 \%$ \\
\hline
\end{tabular}

Sensitivity: $100.00 \%$ ( 95 CI 75.75TO 100).

Specificity: $94.44 \%$ (95 CI 74.24 to 99.01 ).

FPR: $5.56 \%$ (95 CI -5.02to 16.13).

FNR: $0.00 \%$ (95 CI $0 \%$ to 24.25 ).

PPV: $92.31 \%$ (95 CI 66.69 to 98.63 ).

NPV: $100 \%$ (95 CI 81.57 to 100$)$.

DA: $97 \%$ (95 CI 83.33 to 99.41). 
Table 11: Association of Secondary Tract: Per-Op vs MRI $(\mathrm{N}=30)$

\begin{tabular}{|l|c|c|l|l|}
\hline \multirow{2}{*}{$\begin{array}{l}\text { Secondary } \\
\text { Tract (MRI) }\end{array}$} & \multicolumn{3}{|c|}{$\begin{array}{c}\text { Secondary Tract } \\
\text { (Perop) }\end{array}$} & \\
\cline { 2 - 5 } & Yes & No & $\begin{array}{l}\text { Chi } \\
\text { Square }\end{array}$ & $\begin{array}{l}\text { P- } \\
\text { Value }\end{array}$ \\
\hline Yes(N=10) & $8(80 \%)$ & $2(20 \%)$ & & \\
\hline No(N=20) & $1(5 \%)$ & $19(95 \%)$ & & 0.00 \\
\hline
\end{tabular}

MRI showed 10 patients with secondary tract but intra operatively $8(80 \%)$ cases had secondary tract and other 2(20\%) were without secondary tact.MRI showed no secondary tract in 20 cases out of which 19 cases $(95 \%)$ hadno secondary tract intra-operatively but $1(5 \%)$ patient had secondary tract intra-operatively $(\mathrm{P}=0.00)$.

Table 12: Predictive Validity of MRI in Identifying Secondary Tract

\begin{tabular}{|l|c|c|c|}
\hline \multirow{2}{*}{ Parameter } & \multirow{2}{*}{ Value } & \multicolumn{2}{|c|}{ 95\% CI } \\
\cline { 3 - 4 } & & Lower & Upper \\
\hline Sensitivity & $88.89 \%$ & $56.5 \%$ & $98.01 \%$ \\
\hline Specificity & $90.48 \%$ & $71.09 \%$ & $97.35 \%$ \\
\hline FPR & $9.52 \%$ & $-3.03 \%$ & $22.07 \%$ \\
\hline FNR & $11.11 \%$ & $-9.42 \%$ & $31.64 \%$ \\
\hline PPV & $80.00 \%$ & $49.02 \%$ & $94.33 \%$ \\
\hline NPV & $95.00 \%$ & $76.39 \%$ & $99.11 \%$ \\
\hline DA & $90 \%$ & $74.38 \%$ & $96.54 \%$ \\
\hline
\end{tabular}

Sensitivity: $88.89 \%$ ( 95 CI 56.5 TO 98.0).

Specificity: $90.48 \%$ (95 CI 71.09 to 97.3 ).

FPR: $9.52 \%$ (95 CI 2.65 to 28.9 ).

FNR: $11.11 \%$ (95 CI 1.99 to 4.35 ).

PPV: $80.00 \%$ (95 CI 49.0 to 94.3 ).

NPV: $95.00 \%$ (95 CI 76.3 to 99.1 ).

DA: $90 \%(95$ CI 74.3 to 96.5 ).

Table 13: Association of Abscess: Per-Op vs MRI $(\mathrm{N}=30)$

\begin{tabular}{|l|c|c|c|c|}
\hline \multirow{2}{*}{$\begin{array}{l}\text { Abscess } \\
\text { (MRI) }\end{array}$} & \multicolumn{2}{|c|}{ Abscess(Per-Operative) } & \multicolumn{1}{c|}{ Chi } & $\begin{array}{c}\text { P- } \\
\text { Value }\end{array}$ \\
\cline { 2 - 5 } Yquare & No & 16.010 & 0.00 \\
\hline Yes(N=11) & $10(90.90 \%)$ & $1(9.090 \%)$ & & \\
\hline No(N=19) & $3(15.78 \%)$ & $16(84.21 \%)$ & & \\
\hline
\end{tabular}

MRI showed abscess in 11 subjects, of which 10 cases (90\%) had abscess intra-operatively and $1(9.09 \%)$ patient had no abscess. MRI showed no abscess in 19 subjects out of which 16(84.21\%) had no abscess and 3(15.78\%) had abscess intraoperatively $(\mathrm{p}=0.00)$.

Table 14: Predictive Validity of MRI in Identifying Abscess

\begin{tabular}{|l|c|c|c|}
\hline \multirow{2}{*}{ Parameter } & \multirow{2}{*}{ Value } & \multicolumn{2}{|c|}{ 95\% CI } \\
\cline { 3 - 4 } & & Lower & Upper \\
\hline Sensitivity & $76.92 \%$ & $54.02 \%$ & $99.82 \%$ \\
\hline Specificity & $94.12 \%$ & $73.02 \%$ & $98.95 \%$ \\
\hline FPR & $5.88 \%$ & $1.05 \%$ & $26.98 \%$ \\
\hline FNR & $23.08 \%$ & $0.173 \%$ & $45.97 \%$ \\
\hline PPV & $90.91 \%$ & $62.27 \%$ & $98.38 \%$ \\
\hline NPV & $84.21 \%$ & $62.43 \%$ & $94.48 \%$ \\
\hline DA & $87 \%$ & $74.50 \%$ & $98.83 \%$ \\
\hline
\end{tabular}

Sensitivity: 76.92\%( 95 CI 54.0TO 99.8).

Specificity: $94.12 \%$ (95 CI 73.0 to 98.9 ).

FPR: $5.88 \%$ (95 CI 1.0to 26.9).

FNR: $23.08 \%(95$ CI 0.17 to 45.9 ).

PPV: $90.91 \%$ (95 CI 62.2 to 98.3 ).

NPV: $84.21 \%$ (95 CI 62.4 to 94.8 ).

DA: $87 \%(95$ CI 74.5 to 98.8 ).

Table 15: Association of Horseshoe:Per-op vs MRI (N=30)

\begin{tabular}{|l|c|c|c|c|}
\hline \multirow{2}{*}{$\begin{array}{l}\text { Horseshoe } \\
\text { (MRI) }\end{array}$} & \multicolumn{2}{|c|}{$\begin{array}{c}\text { Horseshoe (Per- } \\
\text { Operatively) }\end{array}$} & & \\
\cline { 2 - 5 } & Yes & No & $\begin{array}{c}\text { Chi } \\
\text { Square }\end{array}$ & P-Value \\
\hline Yes(N=1) & $1(100 \%)$ & $0(0 \%)$ & 30.000 & $<0.001$ \\
\hline No(N=29) & $0(0 \%)$ & $29(100 \%)$ & & \\
\hline
\end{tabular}

MRI showed1 case with horse-shoe tract and it was detected intra-operatively $(100 \%)$ $(\mathrm{p}=<0.001)$.

Table 16: Predictive Validity of MRI in Identifying Horse-Shoe Tract

\begin{tabular}{|l|c|c|c|}
\hline \multirow{2}{*}{ Parameter } & \multirow{2}{*}{ Value } & \multicolumn{2}{|c|}{ 95\% CI } \\
\cline { 3 - 4 } & & Lower & Upper \\
\hline Sensitivity & $100.00 \%$ & $100 \%$ & $100 \%$ \\
\hline Specificity & $100.00 \%$ & $100 \%$ & $100 \%$ \\
\hline FPR & $0.00 \%$ & $0 \%$ & $0 \%$ \\
\hline FNR & $0.00 \%$ & $0 \%$ & $0 \%$ \\
\hline PPV & $100.00 \%$ & $100 \%$ & $100 \%$ \\
\hline NPV & $100.00 \%$ & $100 \%$ & $100 \%$ \\
\hline DA & $100 \%$ & $100 \%$ & $100 \%$ \\
\hline
\end{tabular}

Sensitivity, Specificity, PPV, NPV, DA: 100\% (CI 100 to 100).

FPR, FNR: 0\% (CI 0\% to 0\%). 
Table 17: Correlation between Lengths of the primary tract as identified by MRI and peroperatively

\begin{tabular}{|l|c|c|c|c|}
\hline \multicolumn{2}{|l|}{ Spaerman Rank Correlation Coeficient } & $\begin{array}{l}\text { Length of the } \\
\text { tract-MRI }\end{array}$ & $\begin{array}{l}\text { Length Of } \\
\text { The Tract- } \\
\text { Per Op }\end{array}$ \\
\hline $\begin{array}{l}\text { Spearman } \\
\text { 's Rho }\end{array}$ & $\begin{array}{c}\text { length of the } \\
\text { tract in(MRI) }\end{array}$ & $\begin{array}{l}\text { Correlation } \\
\text { Coefficient }\end{array}$ & 1.000 & $.985^{* *}$ \\
\cline { 3 - 4 } & P Value &. & $<.001$ \\
\hline
\end{tabular}

Spearman's correlation co-efficient in MRI is 1.000 and intra-operatively it is 0.985 with significant $p$ value $(p=<0.001)$.

\section{Discussion}

The study aimed to identify the anatomy of the fistula during operative surgery in comparison with radio diagnostic method.

In a study done by Kulvinder Singh et al. ${ }^{10} 45$ patients (90\%) were males out of 50 cases, Alexander et al. ${ }^{11}$ study stated that this disease is more predominent in males(66/80 men) (82.5\%), Halligan et al. ${ }^{12}$ study showed that the disease predominantly strikes young adults, and men are more commonly affected. Naglaa Daabis et al. ${ }^{13}$ showed 21 cases were males out of 25 patients in their study population and in our study 26 males (86.67\%) out of 30 cases and remaining 4 were females(13.33\%) and it agrees with the above studies.

Naglaa Daabis et al. ${ }^{13}$ showed that this disease is predominate in the age group of 21-40 years with mean age of 34.8 years, in the study byBuchanan GN et al. ${ }^{14}$ median age group is 37 years and Manar T Alaat El Essawy et al. ${ }^{15}$ study stated the mean age for this disease is 39 years and in our study population showed the age group of 30-39 is more predominate $(11 / 30)$ with the mean age of 38.4 years.

With regard to total duration of hospital stay, 7 cases stayed for one day(23.33\%), 9 cases stayed for 2 days(30\%), 9 cases stayed for 3 days(30\%), 4 cases stayed for 4 days(13.33\%), and 1 patient stayed for $\max 8$ days(3.33\%) as the patient developed urinary incontinence post-operatively . Perianal discharge is the most common symptom in our study population $(73.33 \%)$ and then followed by perianal pain $(66.67 \%)$. Sainio p et al. $^{4}$ stated that the most frequent clinical presentation is either discharge (seen in about $65 \%$ patients) or pain in the perianal region and its agreed with our study.

Co-morbidities in our study population, 1 case had hypothyroidism $(3.33 \%), 6$ cases had hypertension (20\%), 3 cases had diabetes mellitus(10\%), and 3 patients had coronary artery disease $(10 \%)$.

We classified the primary tract according to park's classification, 25 cases were inter-sphincteric $(83.33 \%)$, and 5 cases were trans-sphincteric $(16.66 \%)$ in MRI and there were no supra sphincteric and extra-sphincteric type in our study population. In our study inter-sphincteric type is the most common type (83.33\%).

With regard to primary tract intra operatively, 26 patients were identified as inter-sphincteric (86.66\%), the most common type in our study and 4 patients were identified as trans-sphincteric type $(13.33 \%)$.

In a study done by Naglaa Daabis et al. ${ }^{13}$ depicted the primary tract with sensitivity-100\%; specificity- $86 \%$, Villa $\mathrm{C}$ et al.${ }^{16}$ study stated that MRI is highly accurate for depiction of the primary tract(sensitivity, $100 \%$; specificity, $86 \%$ ), Beckingham et al. ${ }^{8}$ depicted in their study as MRI is highly sensitive and specificity for primary tract as $97 \%$ and $100 \%$ respectively,in Beets-Tan et $\mathrm{al}^{17}$ study also the sensitivity and specificity for detecting fistula tracts were $100 \%$ and $86 \%$ respectively, Kulvinder Singh et al. ${ }^{10}$ study the sensitivity and specificity of MRI in correctly detecting the primary tract was found to be $95.56 \%$ and $80 \%$ respectively. In study conducted by Akhtar S et al. ${ }^{18}$ MRI has a sensitivity of $90 \%$, specificity of $100 \%$ and diagnostic accuracy of $90 \%$ in determining type and extent of peri-anal fistula. Manar T Alaat El Essawy et al. ${ }^{15}$ study stated that MRI has sensitivity, specificity, NPV, and PPV for primary tract as $96 \%$.

In our study MRI has sensitivity-96 \%, specificity-100\%, PPV-100\%, NPV-80\% and diagnostic accuracy $-97 \%$ for detecting the type of primary tract which is almost agreed with all above studies. 
With regard to internal opening in MRI, 13 cases $(43.33 \%)$ were found to have internal opening at anterior and 17 cases posteriorly $(56.66 \%)$ and the opening at posterior site is with maximum number in our study population. The location of the level of the internal opening is important since this will determine the extent of sphincter division during fistulotomy.Excessive sphincter division will leads to feacal incontinence.

Intra-operatively 12 patients were identified as internal opening at anterior $(40 \%)$ and in 18 cases internal opening at posterior (60\%) with maximum number.

In a study done by Beets-Tan et al. ${ }^{17}$ who reported sensitivity of $96 \%$, specificity of $90 \%$ and PPV of $90 \%$ of MRI for internal opening, Similarly Barker et al. ${ }^{19}$ study reported that sensitivity of MRI is $80 \%$ in detecting internal openings, in a study done by Stoker et al. ${ }^{20}$ stated that the internal opening was successfully depicted by FS-CE-T1WI and T2WI and STIR images were in agreement with the surgical findings, in the study of Kulvinder Singh et al. ${ }^{10}$ noticed the high sensitivity of MRI in correctly localization of internal opening (95.83\%) and in Manar $\mathrm{T}$ Alaat El Essawy et al. ${ }^{15}$ study the sensitivity, specificity, NPV and PPV for MRI in locating the correct internal location $96 \%$.

In our study for identifying the internal opening MRI has sensitivity-100\%, specificity-94\%, PPV92\%, NPV-100\%, and DA-97\%.

10 cases were noticed to have secondary tracts (33.33\%), 11 cases were of abscess (36.11\%), and 1 case was of horse shoe tract(3.33\%) in MRI.

Intra operatively, 9 cases were with secondary tracts $(30 \%), 13$ cases were with abscess $(43.03 \%)$ and 1 patient was with horse shoe extension $(33.33 \%)$.

Naglaa Daabis et al. ${ }^{13}$ depicted the abscesses with sensitivity- 96\%; specificity- 97\%, Beets-Tan et al., ${ }^{17}$ and Mahjoubi et al. ${ }^{21}$ reported a similar high sensitivity and specificity of $96 \%$ and $80 \%$ respectively for abscess, study conducted by Villa $\mathrm{C}$ et al. ${ }^{16}$ reported that MRI is highly accurate for depiction of

abscesses(sensitivity-96\%; specificity-97\%), Kulvinder Singh et al. ${ }^{10}$ study stated the sensitivity and specificity of MRI in correctly detecting for abscess was $87.50 \%$ and 95.24\% respectively with PPV of $77.78 \%$ and NPV of $97.56 \%$ in correctly detecting abscess. In Manar $\mathrm{T}$ Alaat El Essawy et al. ${ }^{74}$ study the sensitivity, specificity, NPV and PPV for MRI in detecting abscess is $100 \%$.

In our study MRI has sensitivity-76\%, specificity94\%, PPV-90\%, NPV-84\% and diagnostic accuracy- $87 \%$ for identifying abscess.

In a study done by Beets-Tan et al. ${ }^{17}$ who reported sensitivity, specificity and PPV of $100 \%$ for identifying horse shoe tracts.

Barker et al. ${ }^{19}$ reported sensitivity of $97 \%$ for horse shoeing, Kulvinder Singh et al. ${ }^{10}$ study depicted the sensitivity of MRI in correctly detecting the horse-shoeing $(87.50 \%)$ and in Manar $\mathrm{T}$ Alaat El Essawy et al. ${ }^{15}$ study the sensitivity, specificity,NPV and PPV of MRI in identifying horse-shoe extensions is $100 \%$.

In our study population the sensitivity, specificity, NPV, PPV and diagnostic accuracy for MRI in identifying horse-shoe tracts is $100 \%$ which is agreeing with all above studies.

In a study done by Mahjoubi et al. ${ }^{21}$ who reported sensitivity and specificity of 80 and $100 \%$ respectively for identifying secondary tracts and in the study of Kulvinder Singh et al. ${ }^{10}$ the sensitivity of MRI in identification of secondary tract $(93.75 \%)$ and in our study MRI has sensitivity$88 \%$, specificity-90\%, PPV-80\%, NPV-95\%, and diagnostic accuracy- $90 \%$ for identifying secondary tracts.

The length of primary tract measured in MRI and intra-operatively showed significant correlation which was done by spearman's correlation coefficient,in MRI it is 1.000 and intra-operatively it is 0.985 with significant $p$ value $(p=<0.001)$.

\section{Conclusion}

MRI is a useful procedure for successful management of perianal fistula by correct assessment of the extent of disease and 
relationship to sphincter complex. Also it helps in identification of secondary extensions, particularly horseshoe tracts and abscesses resulting in complete evaluation and highest possible diagnostic accuracy aiding successful surgical interventions, aiming to reduce complications and recurrences.

With current level of advancement of imaging science, MRI is able to adequately evaluate and classify perianal fistula disease with a high degree of accuracy. The use of multiplanar coil arrays and the use of multiple imaging planes and sequences significantly maximize MRI analysis.

\section{References}

1. Khera PS, Badawi HA, Afifi AH. MRI in perianal fistulae. The Indian journal of radiology \& imaging. 2010 Feb;20(1):53.

2. Henrichsen $S$, Christiansen J. Incidence of fistula-in-ano complicating anorectal sepsis: a prospective study. British journal of surgery. 1986 May 1;73(5):371-2.

3. Vasilevsky CA, Gordon PH. The incidence of recurrent abscesses or fistula-in-ano following anorectal suppuration. Diseases of the Colon \& Rectum. 1984 Feb 1;27(2):126-30.

4. Sainio P. Fistula-in-ano in a defined population. Incidence and epidemiological aspects. InAnnales chirurgiae et gynaecologiae 1983 Dec (Vol. 73, No. 4, pp. 219-224).

5. Sözener U, Gedik E, Aslar AK, Ergun H, Elhan AH, Memikoglu O, Erkek AB, Kuzu MA. Does adjuvant antibiotic treatment after drainage of anorectal abscess prevent development of anal fistulas? A randomized, placebocontrolled, double-blind, multicenter study. Diseases of the Colon \& Rectum. 2011 Aug 1;54(8):923-9.

6. Lilius HG. Fistula-in-ano, an investigation of human foetal anal ducts and intramuscular glands and a clinical study of 150 patients. Acta chirurgica
Scandinavica. Supplementum.

1967

Dec;383:7-88.

7. Choen S, Phillips RK. Insights gained from the management of problematical anal fistulae at St. Mark's Hospital, 198488. British Journal of Surgery. 1991 May 1;78(5):539-41.

8. Beckingham IJ, Spencer JA, Ward J, Dyke GW, Adams C, Ambrose NS. Prospective evaluation of dynamic contrast enhanced magnetic resonance imaging in the evaluation of fistula in ano. British journal of surgery. 1996 Oct 1;83(10):1396-8.

9. Buchanan $\mathrm{G}$, Halligan S, Williams A, Cohen CR, Tarroni D, Phillips RK, Bartram CI. Effect of MRI on clinical outcome of recurrent fistula-in-ano. The Lancet. 2002 Nov 23;360(9346):1661-2.

10. Singh K, Singh N, Thukral CL, Singh KP, Bhalla V. Magnetic resonance imaging (MRI) evaluation of perianal fistulae with surgical correlation. Journal of clinical and diagnostic research: JCDR. 2014 Jun;8(6):RC01.

11. Alexander N, Sanniyasi S, Joseph J, Paramasivam S. A Single Center Study of 80 Cases of Fistula-in-ano. Int J Sci Stud 2016;4(8):122-125.

12. Halligan S, Stoker J. Imaging of fistula in ano 1. Radiology. 2006 Apr;239(1):18-33.

13. Daabis N, El Shafey R, Zakaria Y, Elkhadrawy O. Magnetic resonance imaging evaluation of perianal fistula. The Egyptian Journal of Radiology and Nuclear Medicine. 2013 Dec 31;44(4):705-11.

14. Buchanan GN, Halligan S, Williams AB, Cohen CR, Tarroni D, Phillips RK, Bartram CI. Magnetic resonance imaging for primary fistula in ano. British journal of surgery. $2003 \mathrm{Jul}$ 1;90(7):877-81.

15. Alaat El Essawy MT, Magnetic Resonance Imaging in Assessment of Anorectal Fistulae and its Role in Management. J Gastroint Dig Syst 2013; 3: 139. 
16. Villa C, Pompili G, Franceschelli G, Munari A, Radaelli G, Maconi G, Cornalba GP. Role of magnetic resonance imaging in evaluation of the activity of perianal Crohn's disease. European journal of radiology. 2012 Apr 30;81(4):616-22.

17. Beets-Tan RG, Beets GL, van der Hoop AG, Kessels AG, Vliegen RF, Baeten CG, van Engelshoven JM. Preoperative MR Imaging of Anal Fistulas: Does It Really Help the Surgeon? 1. Radiology. 2001 Jan;218(1):75-84.

18. Akhtar S, Rana A, Latif U, Saleem H, Chaudhary MY. MRI in the pre operative evaluation of perianal fistula. Journal of Postgraduate Medical Institute (PeshawarPakistan). 2014 Jul 25;28(3).

19. Barker PG, Lunniss PJ, Armstrong P, Reznek RH, Cottam K, Phillips RK. Magnetic resonance imaging of fistula-inano: technique, interpretation and accuracy. Clinical radiology. 1994 Jan 1;49(1):7-13.

20. Stoker J, Rociu E, Wiersma TG, Lameris JS. Imaging of anorectal disease. British journal of surgery. 2000 Jan 1;87(1):10-27.

21. Mahjoubi B, Haizadch Kharazi H, Mirzaei R, Moghimi A, Changizi A. Diagnostic accuracy of body coil MRI in describing the characteristics of perianal fistulas. Colorectal Disease. 2006 Mar 1;8(3):2027. 